This item was submitted to Loughborough's Research Repository by the author.

Items in Figshare are protected by copyright, with all rights reserved, unless otherwise indicated.

\title{
Cost efficiency and electricity market structure: a case study of OECD countries
}

PLEASE CITE THE PUBLISHED VERSION

https://doi.org/10.1016/j.eneco.2017.05.005

PUBLISHER

(C) Elsevier

VERSION

AM (Accepted Manuscript)

\section{PUBLISHER STATEMENT}

This work is made available according to the conditions of the Creative Commons Attribution-NonCommercialNoDerivatives 4.0 International (CC BY-NC-ND 4.0) licence. Full details of this licence are available at: https://creativecommons.org/licenses/by-nc-nd/4.0/

\section{LICENCE}

CC BY-NC-ND 4.0

\section{REPOSITORY RECORD}

Ajayi, Victor, Thomas G. Weyman-Jones, and Anthony Glass. 2019. "Cost Efficiency and Electricity Market Structure: A Case Study of OECD Countries". figshare. https://hdl.handle.net/2134/25134. 
Cost Efficiency and Electricity Market Structure: A Case Study of OECD Countries

\author{
Victor Ajayi ${ }^{\mathrm{a} 1}$, Thomas Weyman-Jones and Anthony Glass \\ School of Business and Economics, Loughborough University, \\ Leicestershire, United Kingdom
}

\begin{abstract}
The OECD electricity sector has witnessed significant institutional restructuring for the past three decades. As a consequence, many power generation utilities now act as unregulated companies that technically compete to sell power on an open market. This paper analyses the performance in term of cost efficiency for electricity generation in OECD power sector while accounting for the impact of electricity market structures. We employ the short-run cost function in which capital stock is treated as a quasi-fixed factor input. Empirical models are developed for the cost function as a translog form and analysed using panel data of 25 countries during the period 1980 to 2009. Our results show that cost efficiency scores as well as their ranking are sensitive to the choice of model specification. We show that it is necessary to model latent country-specific heterogeneity in addition to time-varying inefficiency. The estimated economies of scale are adjusted to take account of the importance of the quasi-fixed capital input in determining cost behaviour, and long run constant returns to scale are verified for the OECD generation sector. The research findings suggest there is a significant impact of electricity market regulatory indicators on cost. In particular, public ownership and vertical integration are found to have significant and sizable increasing impacts on cost, thereby indicating policy lessons on the desirable ways to implement structural electricity generation reforms.
\end{abstract}

Keywords: Cost efficiency, stochastic frontier, heterogeneity, market reform indicators JEL Classification: C23, D24, L94, L51,

\footnotetext{
${ }^{1}$ Correspondence author Email: $\underline{\text { V.Ajayi@lboro.ac.uk }}$
} 


\section{Cost Efficiency and Electricity Market Structure: A Case Study of OECD Countries}

\section{Introduction}

Due to the liberalisation and deregulation wave in the electric power industry across most of the countries in the world, electricity generation companies, especially in the several OECD countries now act as unregulated companies that technically compete to sell power on an open market. An overview of experiences in several OECD countries where generation segment has largely been deregulated while transmission and distribution continue to be regulated is provided by Al-Sunaidy \& Green (2006) andJoskow (2008). One compelling reason for the deregulation of electricity generation as against direct economic regulation is the lack of natural monopoly in this segment ${ }^{2}$ which is the common feature of transmission and distribution. This policy choice along with horizontal restructuring of the segment have been accompanied by increased number of competing generators to mitigate market power and to ensure that wholesale markets are reasonably competitive. The recent history of the electricity generation industry has been characterised in many countries by privatization, deregulation and liberalization. Although these changes are often given the convenient overall titles of deregulation or open markets, these can be misleading and these changes can be significantly different in scope and meaning. It should be clear that while such policy induced changes can occur together, they do not mean the same thing ${ }^{3}$.

By privatization, we mean the conversion of state owned or publicly owned utilities into investor owned utilities. By deregulation, we mean the decision by government to step back from the day-to-day determination of pricing and investment decisions. The alternative to direct government control is to appoint a regulatory agency which is independent but accountable to government and which is responsible for regulating the natural monopoly aspects of the industry which arise from the importance of economies of scale and scope. By liberalization, we mean the opening of the market to new entrants and the permission of incumbents to demerge into competing firms or alternatively to merge or even exit the industry. The model here is of a competitive industry where entry and exit are relatively free and of low cost, thereby reducing the need for extensive or intensive regulation by a NRA.

These forms are not synonymous with each other and may occur to varying degrees in the power generation industry at different times. In Scandinavian countries publicly owned utilities exist within a deregulated and liberalised market and in Germany there are many municipal level publicly owned utilities within a deregulated and partly privatised market for power networks.

The generation of electricity involves using different ranges of technology and fuel. To a great extent, fossilfuel-fired boilers producing steam for turbine generators remain the major electricity generation technology.

\footnotetext{
${ }^{2}$ Electricity production is conventionally segmented into generator, (HV) transmission, (LV) distribution and retail supply.

${ }^{3}$ We are grateful to a referee for encouraging us to emphasise these distinctions.
} 
These generation technologies are characterised by quasi-fixed inputs which implies that they cannot be immediately adjusted. Another important characteristic of electricity infrastructures is that its current technology is a consequence of investment decisions made in the past and whose effects resonate over various periods ${ }^{4}$. Nelson (1985) argues that the nature of the generation facilities in the electric power industry could result in the firm not operating on the economic expansion paths. Since estimations of economic of scale in this industry have been based on long-run cost which implicitly or explicitly invoke the assumption of cost minimization, this assumption will be violated. The need to account for such quasi-fixed inputs is therefore important in estimating scale economies to avoid imprecise and biased cost function parameters.

Analysis of electricity generation cost structure and efficiency is made more imperative in the understanding of the behaviour of power generators in relation to environmental and social welfare aspects. Electricity is a non-storable commodity in which requires balancing of power generated and consumed on an electric grid on a second by-second basis. The ability of these generators to adjust their generating capacity, and hence the output at will many times is constrained and could be slowed down in the presence of suboptimal capacity factors like cost associated with such adjustments, administrative regulation, external factor and time. Therefore, cost structure analysis may help to reduce technical and economic inefficiency and enhance improving social benefit. This could perhaps necessitate mergers of power generators who are not operating optimally in order to reduce operation costs since success of competition rests on the size and number of generators in the market.

One of the major contributors of global greenhouse gas emissions is electric power generation, accounting for 42\% the global energy related CO2 emissions and its associated externalities in 2011 (IEA, 2013). While focusing on how efficient power utilities are in generating electricity, it is also crucial to understand how well they manage to avoid unnecessarily large production levels of these bad outputs. Carbon emission produced by electricity generator are endogenous in the production process since they are considered a joint output of electric power plants alongside with electricity generation output. Reducing these environmental costs is associated with decreasing generation output at existing input levels or increases in input costs at desired output levels. Power utilities are concerned that commitment to reducing these bad outputs would eliminate their profit margins and impede their competitiveness with other generators.

To this end, this paper contributes to the empirical literature by assessing the cost efficiency and industry structure of OECD power generation sectors. The remainder of the paper proceeds as follows. Section 2

\footnotetext{
${ }^{4}$ See Díaz-Hernández, et al. (2014) for a similar discussion on ports infrastructure
} 
presents the brief literature review and section 3 details the methodology used in this paper in order to estimate cost function and efficiency. Section 4 presents the data description and section 5 provides the result and discussion. Section 6 presents the concluding remarks and policy recommendation.

\section{Literature review}

A large number of studies have attempted to investigate cost structure and efficiency in electricity industry as evidenced by the proliferation of the methodology. This underscores the growing discourse regarding deregulation of power sector and its attendant gains as advanced by proponents of market reform. Nevertheless, recent empirical findings have shown that cost function parameter estimates of electricity sector differ across many study dimensions such as methodology, data type, model specification, sample size etc. While most of these studies have been dominated by the conventional long run cost minimisation assumption, little attention has been given to sub optimality of capacity as a result of costly adjustment to time profile of electricity demand. For the handful that have considered cost estimation of the industry by taking into account the quasi-fixed input, there is no recognition of the multiproduct nature of power industry where emissions are assumed to be jointly produced with electric power. Most existing empirical applications of the short run cost which allows one to relax the assumption of cost minimization with respect to all inputs in electricity sector have used different functional form with translog functional function form being the most common specification.

A search in the literature shows that cost function empirical analyses have been carried out for the different stages of the industry as each of these stages are marked by different levels of competition and regulation in varying degrees across countries (See Nelson and Wohar, 1983; Kaserman and Mayo, 1991; Nemoto et al., 1993). Most of the articles on the generation stage of the industry are in the context of electricity industry in the U.S. which dates back to the work of Christensen and Greene (1976), using a translog total cost function to estimate scale economies of electric power generating firms. Other such as Nelson (1985, 1989), Kraustmaan and Solow (1988), and Hovde et al (1996) employ a variable cost function to estimate scale economies. Rhine (2001) estimate economies of scale for fossil fuel and nuclear fuel electricity generation using a variable cost function. The result shows that electric utilities are operating on the negatively sloped portion of the long-run average cost curve, indicating either slight economies of scale or no economies of scale. Nemoto et al (1993) also specified the variable cost function as a translog form using panel data of nine Japanese electric utility firms during the period 1981 to 1985. They found most firms experiencing scale economies in the short run but diseconomies in the long run, and certain degree of over-capitalization

Some studies which include Considine (2000), Keith and Terrell, (2001), Maloney (2001), Hiebert (2002) and Rungsuriyawiboon and Stefanou (2007) used data on the steam electric power generation source to 
estimate cost structures and the possible savings in the production costs for major investor owned utilities. Considine (2000) estimates short-and long-run marginal production cost and returns to scale and finds substantial short-run diseconomies of scale at high output levels. Keith and Terrell, (2001) use a Bayesian stochastic frontier model to measure cost efficiency, price elasticities, and returns to scale of 78 steam plants. Their results indicate that plants on average could reduce costs by up to $13 \%$ by eliminating production inefficiency. They show that most plants operate at increasing returns to scale, suggesting further cost savings could be achieved through increasing output. Maloney (2001) applied a translog variable cost function to study electricity generation in the United States. The cost function is estimated using a two dimensional definition of capacity utilization and the result shows that both dimensions affect average cost, which generally declines as capacity utilization increases. Hiebert (2002) finds increasing scale economies in both coal-fired plants and natural gas-fired plants with $20 \%$ and $12 \%$ degree of scale economies respectively. Rungsuriyawiboon and Stefanou (2007) show that most electric utilities underutilized fuel relative to the aggregated labour and the maintenance input, and overutilized capital in production. They concluded that states adopting a deregulation plan improve the performance of utilities in terms of the technical efficiency of variable inputs.

More recent studies such as Wang, Xie, Shang \& Li (2013) identify measures to improve the performance of China's thermal power industry in view of cost efficiency. Assaf, Barros, Managi (2010) analyse and compare the cost efficiency electricity generation Japanese steam power generation utilities using the fixed and random effect Bayesian frontier models. The results show that total cost increases significantly with the input prices and outputs, with the exception of the price of labour and restricting CO2 emissions can lead to a decrease in total cost. Akkemik, (2009) estimates cost functions and investigates the degree of scale economies, overinvestment, and technological progress in the Turkish electricity generation sector for the period 1984-2006 using long-run and short-run translog cost functions. Estimations were done for six groups of firms, public and private. The results indicate existence of scale economies throughout the period of analysis, hence declining long-run average costs.

Empirical studies on the cost structure for the transmission and distribution stages include the work of Kwoka (2005) which used quadratic cost function to examine whether mergers in the US distribution sector which appeared as a consequence of the reforms could enhance cost efficiencies. The findings reveal significant economies at low output levels, holding system size and customer density constant, but the cost gradient is otherwise modest. It also shows that the scale properties of the wires function are significantly stronger than those for the supply function performed by distribution utilities. Yatchew (2000) estimate the costs of distributing electricity using data on municipal electric utilities in Ontario, Canada. Their specifications comprise semiparametric variants of the translog cost function where output enters non- 
parametrically and remaining variables (including their interactions with output) are parametric. The study reveal substantial evidence of increasing returns to scale with minimum efficient scale being achieved by firms with about 20,000 customers while the large firm exhibit constant or decreasing returns. Giles and Wyatt (1993) estimate a total cost function from a sample of 60 New Zealand electricity distributors, reporting an efficient scale for a sales range of 500 to $3500 \mathrm{GWh}$.

Burns and Weyman-Jones (1996) used cost frontier model to estimate efficiency change for 12 regional electricity distributions in the UK. They enumerate factors which determine costs such the maximum demand on the system, number of customers served (main determinants of distribution operating costs), the type of consumer, dispersion of the consumers, size of the distribution area, total kWh sold system security, length of distribution line and the transformer capacity. Their results indicate significant evidence of economies of scale. Kopsakangas-Savolainen and Svento, R. (2008) examine the cost-effectiveness of Finnish electricity distribution utilities employing several panel data stochastic frontier specifications of Cobb-Douglas and Translog model. The study points out the importance of the efficient use of the existing distribution network with the economies of scale results suggesting that firms could reduce their operating costs by using networks more efficiently.

In two different studies of Swiss electricity distribution utilities, Filippini (1996) and Filippini and Wild (2001) using a flexible translog by introducing a quasi-fixed cost, representing the impacts of quasi-fixed distribution equipment and a linear average cost function find evidence of increasing scale economies throughout their sample of 39 and 59 utilities respectively. Filippini (1998) also show the existence of economies of density for most output levels for 39 Swiss municipal distribution utilities while economies of scale appear for small and medium-sized utilities with policy a recommendation for mergers among the utilities. Pollitt et al (2005) examine the relative performance of electricity distribution systems in the UK and Japan between 1985 and 1998 using cost-based benchmarking with data envelopment analysis (DEA) and stochastic frontier analysis (SFA) methods and suggest that the productivity gain in the UK electricity distribution has been larger than in the Japanese sector.

Furthermore, some studies also provide empirical evidence for the whole industry. Arcos and De Toledo (2009) examined eleven Spanish vertically integrated utilities and find the presence of economies of scale, the effect of technological progress and the differences in the efficiency of the different firms within the market. They concludes that the Spanish electrical utility industry was not, in fact, characterized by economies of scale during this period, but witnessed a great improvement in efficiency within that period. Fraquelli and Vannoni (2005) investigate cost savings from generation and distribution of Italian electric 
utilities. The study finds evidence of both multi-stage economies of scale and vertical economies and suggests that a complete divestiture policy would entail efficiency losses.

Considering the theoretical supposition of deregulation which assumes exhaustions of economics of scale for generation ${ }^{5}$, there is a need to further investigate this argument from the point of view of cross country analysis. Thus the present study contributes to existing literature in threefold. First, unlike previous studies which are centred on country level analysis, the present study focuses exclusively on cost estimates from generation segments in OECD countries with broader geographical coverage to enhance a better understanding of the cost structures among these estimates in OECD countries electricity generation and attributes of studies reporting these estimates in the individual countries in the market economies. Second, we investigate the impact of electricity market structure on cost efficiency by incorporating electricity reform regulatory index in our analysis. Third, unlike previous studies, we extend our model to include multiproduct function by including carbon emission as part of the outputs of electricity generation in order to estimate and provide reliable information on some cost characteristics of generation such as cost complementarity, non-jointness etc.

\section{Methodology}

An electricity utility produces a vector of outputs including desirable products generated in the production process, and undesirable products, i.e. that part of production that constitutes environmental pollution. The output of electricity during the production process is dependent upon inputs such as stock of capital from generating capacity, labour and primary fuels.

Let $\mathbf{y} \in \mathfrak{R}_{+}^{m}$ represents an $m$-dimensional vector of outputs produced from an $n$-dimensional input vector $\mathbf{x} \in \mathfrak{R}_{+}^{n}$. Outputs are determined exogenously in order to meet market demand. The production process can be characterised by an additional variable $t$, which denotes the level of technology and which uses time as a proxy.

Estimating the structure of a cost function requires an explicit assumption regarding the state of equilibrium, long run when all inputs are variable and short run when the capital stock may be difficult to adjust. Adjustments in the capital stock are relatively costly and power utilities are obliged to respond to all the demand, and thus they typically dispose of excess capacities to account for seasonal and unexpected demand variations. Power utilities can be affected by investment constraints, regulation or indivisibilities which could make immediate adjustment difficult in the short run. These situations reflect the quasi-fixity of

\footnotetext{
${ }^{5}$ Landon(1983) and Joskow (1996) for a discussion of the assumption of technology and cost structures of different segments of the power sector.
} 
capital stock. Faced with this situation, the economic decision of the firm in the industry will, at any given moment, be to minimise cost by only employing the optimal quantities of the easily adjustable variables inputs (i.e. labour and fuel), given the existing levels of the quasi-fixed input (i.e. capital stock). Therefore, it is important to recognise this fact and differentiate between variable and quasi-fixed inputs when evaluating cost efficiency of electric power utility. To account for this peculiar quasi-fixity characteristic of capital stock, we employ a short-run equilibrium model which assumes capital as quasi-fixed input while the utility uses the most efficient level of other variable inputs.

Therefore, we proceed by differentiating capital stock as input which is a quasi-fixed input in the short run and variable in the long run, and symbolise it with $z_{o}$, with input price: $w_{0}$. Then, following the arguments in Friedlander and Spady (1981) and Braeutigam and Daughety (1983), we can write the long run cost function, with all inputs including capital stock treated as variable, in the form

$C\left(\boldsymbol{y}, \boldsymbol{w}, w_{0} t\right)=\min _{\mathbf{z}_{0}, \mathbf{x}}\left\{w_{o} z_{o}+\boldsymbol{w}^{\prime} \mathbf{x}: f\left(\mathbf{y}, \mathbf{x}, z_{o}, t\right)=1\right\}$

In the short-run, the capital input available to the firm is assumed to be fixed, implying that the firm attempts to minimize cost conditional on a given plant size. The short run cost function is therefore:

$C^{S}\left(\boldsymbol{y}, \boldsymbol{w}, \boldsymbol{z}_{\mathbf{0}}, \boldsymbol{t}\right)=\min _{\mathbf{x}}\left\{w_{o} z_{o}+\boldsymbol{w}^{\prime} \mathbf{x}: f\left(\mathbf{y}, \mathbf{x}, z_{o}, \mathrm{t}\right)=1\right\}$

(2)

The envelope theorem confirms that the long run total cost defines the envelope of the short run total cost functions. When the firm minimizes the variable cost, $C^{V}$, of producing a given output by optimising the fixed stock of capital, $z_{0}$, then the long run cost function is defined as the envelope of the short run cost functions. In other words when $z_{0}$ is the same as the optimal level of capital that would be chosen in the long run, then

$C\left(\boldsymbol{y}, \boldsymbol{w}_{\mathbf{0}}, \boldsymbol{w}, \boldsymbol{t}\right)=\min _{\mathbf{z}_{\mathbf{0}}} C^{V}\left(\boldsymbol{y}, \boldsymbol{z}_{\mathbf{0}}, \boldsymbol{w}, \boldsymbol{t}\right)+w_{o} z_{o}=C^{S}\left(\boldsymbol{y}, \boldsymbol{z}_{\mathbf{0}}, \boldsymbol{w}, \boldsymbol{t}\right)$

Equation (3) above is the tangency condition between the short and long run total cost curves. Thus, the envelope theorem implies that for any slight deviation of the level of the fixed input above or below the optimal level, there will be no reduction in total cost.

The short run cost function $C^{s}\left(\boldsymbol{y}, \mathbf{z}_{\mathbf{0}}, \boldsymbol{w}, \boldsymbol{t}\right)$, differs from the used long run cost function because the price of capital appears as an explanatory variable in the long run cost function, while the stock of capital appears as 
an explanatory variable in the short run cost function. The short run cost function, $C^{S}$ (.) for electric power generation depends upon two variable factor prices: fuel prices and labour prices, conditional upon predetermined levels of capital stocks $z_{\mathbf{0}}$, electricity generation, $\mathbf{y}$ and the state of technology $t . C^{s}($.$) is non-$ negative and non-decreasing in $\mathbf{y}$, homogenous of degree one, non-decreasing, and concave in the variable factor input prices, and non-increasing and convex in the levels of quasi-fixed factors $\boldsymbol{z}_{\mathbf{0}}$.

Differentiating (3) at the point where $z^{*}$ represents the optimal value of fixed inputs which minimises the short run total cost, then

$\left(\frac{\partial C\left(\boldsymbol{y}, \boldsymbol{w}_{\mathbf{0}}, \boldsymbol{w}, \boldsymbol{t}\right)}{\partial z_{\mathbf{0}}}\right)_{z_{\mathbf{0}}=z^{*}}=0=\left(\frac{\partial C^{V}\left(\boldsymbol{y}, \mathbf{z}_{\mathbf{0}}, \boldsymbol{w}, \boldsymbol{t}\right)}{\partial z_{\mathbf{0}}}\right)_{\mathbf{z}_{\mathbf{0}}=z^{*}}+w_{O}$

Rearranging Equation (4) gives the important interpretation of the shadow price of the capital input

$\left(\frac{\partial C^{V}\left(\boldsymbol{y}, \mathbf{z}_{0}, \boldsymbol{w}, \boldsymbol{t}\right)}{\partial \mathbf{z}_{\mathbf{0}}}\right)_{z_{\mathbf{0}}=z^{*}}=-w_{O}$

Equation (5) implies that, in the long run equilibrium, cost minimisation is accomplished when variable cost saved by substituting the last unit of capital for variable inputs is equal to the price of capital, $w_{o}$. This allows us to interpret the derivative on the left-hand-side of (5), i.e. the effect on the variable cost function of a change in the quasi-fixed input of capital as the negative of the shadow price of capital. If the derivative is expressed in log or elasticity terms then it corresponds to the negative of the shadow rate of return on capital. This is the core argument of Breautigam and Doherty (1984).

If $\frac{\partial C^{V}\left(\boldsymbol{y}, \boldsymbol{z}_{0}, \boldsymbol{w}, \boldsymbol{t}\right)}{\partial \mathbf{z}_{\mathbf{0}}}$ is less than $-w_{o}$ i.e. negative and greater in absolute value magnitude, it implies suboptimal capital whereas if $\frac{\partial C^{V}\left(\boldsymbol{y}, \mathbf{z}_{0}, \boldsymbol{w}, \boldsymbol{t}\right)}{\partial \mathbf{z}_{\mathbf{0}}}$ is larger than- $w_{o}$, it means excess capital. There is a possibility of $\frac{\partial C^{V}\left(\boldsymbol{y}, \mathbf{z}_{0}, \boldsymbol{w}, \boldsymbol{t}\right)}{\partial z_{0}}$ being positive, implying over-investment in capacity generation and could potentially results in a situation where electric power utility does not operate at a long run efficiency position ${ }^{6}$.

The shadow price of the quasi-fixed input is important for estimating the degree of scale economies which is a long run parameter by definition. Panzar and Willig (1977) show the measure of degree ray (or overall) scale economies, $r$, at output vector $y$ from the multi-product firm is derived from the long run cost function as;

\footnotetext{
${ }^{6}$ For a discussion of the interpretation of the enveloped conditions, see Cowing and Holtmann (1983).
} 
$r=\frac{\left.C\left(\boldsymbol{y}, \boldsymbol{w}_{\mathbf{0}}, \boldsymbol{w}, \boldsymbol{t}\right)\right)}{\sum_{r=1}^{R} y_{i} M C_{i}}=\frac{1}{\sum_{r=1}^{R} \varepsilon_{C y_{r}}}$

where, $M C_{r}$ is the marginal cost with respect to the individual output, and $\varepsilon_{C y_{r}}$ are cost elasticities of individual outputs. If applied directly to the short run cost function, this measure is invalid as an estimate of the long run scale elasticity parameter. However, in the presence of a quasi-fixed input, Braeutigam and Daughhety, (1983) show that scale economies can be calculated from the short run cost function by adjusting the Panzar and Willig measure by the shadow price of the quasi-fixed input:

$r *=\left(1-\frac{\partial \ln C^{s}\left(\boldsymbol{y}, \mathbf{z}_{0}, \boldsymbol{w}, \boldsymbol{t}\right)}{\partial \ln z_{0}}\right) / \sum_{i=1}^{n} \frac{\partial \ln C^{s}\left(\boldsymbol{y}, \mathbf{z}_{0}, \boldsymbol{w}, \boldsymbol{t}\right)}{\partial \ln y_{i}}$

Where $\mathbf{z}_{\mathbf{0}}=z^{*}$ is the optimal level of capital stock in for a given output produced. Ray scale economies are present when the calculated value of $r$ exceeds one, while if $r$ equals one there are long run constant returns to scale and decreasing returns to scale if $r$ is less than one. Caves et al. (1981) also proposed an alternative approach of inferring economies of scale based on direct estimation of the variable cost function:

$r *=\left(1-\frac{\partial \ln C^{V}(.)}{\partial \ln z_{0}}\right) / \sum_{i=1}^{n} \frac{\partial \ln C^{V}(.)}{\partial \ln y_{i}}$

The scale economies in this case are based on the actual capital stock, rather than the optimal value of the fixed capital input. Scale economy estimates computed using the second method may not coincide with those derived using the first (Vita, 1990). The key point is that if the unadjusted Panzar-Willig estimator is applied in a variable cost estimation, the result will indicate only the curvature of the short run total cost function, which is likely in a capital intensive industry such as electricity generation to be much steeper than the curvature of the long run cost function. Consequently in evaluating scale economies is it critical that we make the adjustment for the shadow price of the quasi-fixed input.

The studies on stochastic frontier cost (production) decomposes deviations from these frontiers into random noise and inefficiency terms while estimating efficiency based on the independent proposition of Aigner et al. (1977) and Meeusen and van den Broeck (1977). In order to investigate empirically cost inefficiency in electricity generation in OECD countries, we employ multi-product cost function model. We have the following stochastic frontier cost models with:

$$
C_{i t}=f\left(\boldsymbol{y}, \mathbf{z}_{\mathbf{0}}, \boldsymbol{w}, \boldsymbol{t}\right)_{i t}+u_{i t}+v_{i t}
$$

where $C_{i t}=$ is the cost for the $i$ th OECD country national generation at the time $t, i=1, \ldots 25$ and $\mathrm{t}=$ $1, \ldots 30, \boldsymbol{y}_{i t}$ is a vector for the outputs, $\boldsymbol{w}_{i t}$ is a vector for the factor prices, $\boldsymbol{z}_{\mathbf{0 i t}}$ is a quasi-fixed input. Since 
the mean of the variables are regarded as the expansion point, costs as well as outputs and factor prices are normalise by dividing the variables by their corresponding means. $u_{i t}$ represents one-side technical inefficiency, whereas $v_{i t}$ denotes two-sided convectional idiosyncratic error term with zero means and variance $\sigma_{v}^{2}$.

Several flexible functional forms have been proposed, which help to address the drawback associated with previous inflexible functional forms such as Cobb-Douglas based on constant elasticities of substitution criticized by Uzawa (1962) ${ }^{7}$. It is worth noting that these functional forms are not parsimonious (in terms of number of parameters) and more cumbersome to implement empirically ${ }^{8}$. The most popular and widely used specification of these flexible functional forms in stochastic frontier cost literatures has been translog form ${ }^{9}$. Using the transcendental logarithm functional form as an arbitrary second order approximation to the multiproduct cost function, we fit variable cost functions (i.e. a function for the minimum cost required to produce outputs given the input prices), $C\left(y, z_{0}, w, t\right)$, for $N$ countries over $T$ periods. The condition that the cost function is homogenous of degree one in input prices is imposed by normalising cost and fuel price by the price of labour (this choice is suggested by the fact that the sample variance of the price of fuel exceeds that of the price of labour).. The estimated cost function is specified as follows:

$$
\begin{aligned}
& \ln \left(C_{i t} / w_{J i t}\right)=\alpha_{0}+\sum_{m=1}^{M} \alpha_{m} \ln \left(y_{m i t}\right)+\frac{1}{2} \sum_{m=1}^{M} \sum_{n=1}^{M} \alpha_{m n}\left(\ln \left(y_{m i t}\right) \ln \left(y_{\text {nit }}\right)\right) \\
& +\sum_{j=1}^{J-1} \beta_{j} \ln \left(w_{j i t} / w_{J i t}\right)+\frac{1}{2} \sum_{j=1}^{J-1} \sum_{k=1}^{J-1} \beta_{j k}\left(\ln \left(w_{j i t} / w_{J i t}\right) \ln \left(w_{\text {kit }} / w_{J i t}\right)\right) \\
& +\sum_{m=1}^{M} \sum_{j=1}^{J-1} \gamma_{m j}\left(\ln \left(y_{m i t}\right) \ln \left(w_{j i t} / w_{J i t}\right)\right)+\delta_{1} t+\frac{1}{2} \delta_{2} t^{2} \\
& +\sum_{m=1}^{M} \theta_{m} \ln \left(y_{m i t}\right) t+\sum_{j=1}^{J-1} \mu_{j} \ln \left(w_{j i t} / w_{J i t}\right) t+\pi_{1} \ln \left(z_{0 i t}\right)+\frac{1}{2} \pi_{2}\left(\ln \left(z_{0 i t}\right)\right)^{2} \\
& +\sum_{m=1}^{M} \rho_{m}\left(\ln \left(y_{m i t}\right) \ln \left(z_{0 i t}\right)\right)+\sum_{j=1}^{J-1} \sigma_{j}\left(\ln \left(w_{j i t} / w_{J i t}\right) \ln \left(z_{0 i t}\right)\right)+\varepsilon_{i t}
\end{aligned}
$$

\footnotetext{
${ }^{7}$ Uzawa (1962) proved that it is impossible for any functional form that exhibits constant elasticities of substitution to provide simultaneously the capability to attain an arbitrary set of elasticities.

${ }^{8}$ A functional form is parsimonious if it provides a second order approximation using a minimal number of parameters. See Fuss, McFadden, and Mundlak (1978) which argue that a growing number variables leads to more parameters estimates which exacerbate problems of multicollinearity. Also, when the sample is small, excess parameters mean a loss of freedom and hence a loss in the precision of estimation.

${ }^{9}$ See Christensen, Jorgenson and Lau $(1971,1973)$ for discussion on the rationale for preference towards the translog functional form.
} 
The cost function in (10) is estimated using three stochastic frontier estimation models that are different based on the assumptions imposed on the error term $\left(\varepsilon_{i t}\right)$, inefficiency and error term. These models are summarised Table 1, and explained below.

Model I: TI is the time-invariant fixed effects model proposed by Schmidt and Sickles (1984) .The model specifies a firm-specific effect $u_{i}$, an independent randomly distributed intercept, and a random noise term $v_{i t}$ which isassumed to be identically and independently distributed (iid). The advantage of this model is that it avoids making any distributional assumption about the inefficiency term, and it permits the inefficiency term to be correlated with the regressors. The disadvantage is the inability to distinguish between time-invariant unobserved heterogeneity and cost inefficiency as all time-invariant firm-specific effects are incorporated into inefficiency. A country i's inefficiency is assumed to be interval between its estimated fixed effect and that of the country on the frontier namely, the minimum estimated fixed effect.

Model II, TFE is the true fixed effects stochastic frontier analysis of Greene (2005) which relaxes the restrictive assumption in model I by allowing time variation in the inefficiency term while enabling investigation of the impact of observed heterogeneity on cost and efficiency. If latent heterogeneity exists such as factors that beyond the firms' control but may affect their costs and if not adequately accounted for, then all the time invariant heterogeneity will be pushed to the intercepts and finally into the inefficiency term leading to biased efficiency estimate. The unobserved firm-specific heterogeneity can be taken into account with conventional fixed or random effects in a panel data model. In order to distinguish external heterogeneities from cost efficiency, the "true” fixed effect model incorporates an additional stochastic term representing inefficiency. Model II addresses the time invariant heterogeneity by specifying separate intercept dummy variables for each unit in the sample and follows the asymmetric half normal distribution or the asymmetric exponential distribution for the cost inefficiency component and normal distribution for the error term. This model is estimated using Maximum Likelihood estimation.

In model II, a time-invariant component of inefficiency has been omitted. Model III, FWEC proposed by Kumbhakar, Lien and Hardbaker (2014) deals with the possibility of time-invariant inefficiency by separating time-invariant (persistent) inefficiency from time-invariant heterogeneity. The extended model includes separate four components; two which are stochastic inefficiency terms (residual and persistent inefficiencies) and other two are time invariant heterogeneity and idiosyncratic error term. This model is specified as follows;

$\ln C_{i t}=\alpha_{o}+f\left(\mathbf{y}_{i t}{ }^{\prime}, \mathbf{w}_{i t}{ }^{\prime}\right)+\pi\left(\mathbf{z}_{i t}\right)+\gamma_{i}+\eta_{i}+v_{i t}+u_{i t}$ 
where $\gamma_{i}$ are the random firm effects that capture unobserved time-invariant heterogeneities, $\eta_{i}$ timeinvariant (persistent) inefficiency, $v_{i t}$ is idiosyncratic error term and $u_{i t}$ is the time-varying (residual) inefficiency. The overall cost efficiency is the given as the product of time-invariant (persistent) efficiency and time-varying (residual) efficiency. The consideration for model III becomes more relevant in the context of quasi-fixed input to the extent that inefficiency associated with this input may not be eliminated in the short run and tends to remain with the firm over time. This model is estimated using Pseudo-Maximum Likelihood methods originally suggested by Fan et al (1996) which involves a four step modelling procedure, in which the first step is the one-way random effects feasible generalised least squares estimator. The cost efficiency score for each country can be estimated from the conditional expectations proposed by Jondrow et al. (1982).

\begin{tabular}{|c|c|c|c|}
\hline $\begin{array}{l}\text { Table } 1 \text { estimation } \\
\text { models } \\
\text { Specification }\end{array}$ & $\begin{array}{l}\text { Model } 1 \text { (TI) } \\
\text { Schmidt-Sickles (1984) }\end{array}$ & $\begin{array}{l}\text { Model } 2 \text { (TFE) } \\
\text { Greene (2005) }\end{array}$ & $\begin{array}{l}\text { Model } 3 \text { (FWEC) } \\
\text { Kumbhakar-Lien- } \\
\text { Hardaker (2014) }\end{array}$ \\
\hline Error-component model & $\varepsilon_{i t}=v_{i t}+u_{i}$ & $\varepsilon_{i t}=v_{i t}+\alpha_{i}+u_{i t}$ & $\varepsilon_{i t}=v_{i t}+\eta_{i}+\gamma_{i}+u_{i t}$ \\
\hline Idiosyncratic error & $v_{i t} \sim N\left(0, \sigma_{v}^{2}\right)$ & $v_{i t} \sim N\left(0, \sigma_{v}^{2}\right)$ & $v_{i t} \sim N\left(0, \sigma_{v}^{2}\right)$ \\
\hline $\begin{array}{l}\text { Time-invariant } \\
\text { (persistent) inefficiency }\end{array}$ & $\begin{array}{l}\text { Yes } \\
\text { Fixed Effects, } u_{i}\end{array}$ & No & $\begin{array}{l}\text { Yes } \\
\qquad \eta_{i} \sim N^{+}\left(0, \sigma_{\eta}^{2}\right)\end{array}$ \\
\hline $\begin{array}{l}\text { Country-specific latent } \\
\text { heterogeneity }\end{array}$ & No & $\begin{array}{l}\text { Yes } \\
\text { Fixed Effects, } \alpha_{i}\end{array}$ & $\begin{array}{l}\text { Yes } \\
\text { Random Effects, } \gamma_{i}\end{array}$ \\
\hline $\begin{array}{l}\text { Time-varying (residual) } \\
\text { inefficiency }\end{array}$ & No & $\begin{array}{l}\text { Yes } \\
u_{i t} \sim N^{+}\left(0, \sigma_{u}^{2}\right) \text { or } \\
u_{i t} \sim \text { iid }- \text { exponential }\end{array}$ & $\begin{array}{l}\text { Yes } \\
\qquad u_{i t} \sim N^{+}\left(0, \sigma_{u}^{2}\right)\end{array}$ \\
\hline Inefficiency measure & & & \\
\hline Persistent (time-invariant) & $\hat{u}_{i}-\operatorname{Min}\left\{\hat{u}_{j}\right\}$ & None & $E\left(\eta_{i} \mid \varepsilon_{i t}\right)$ \\
\hline Residual (time-varying) & None & $E\left(u_{i t} \mid \varepsilon_{i t}\right)$ & $E\left(u_{i t} \mid \varepsilon_{i t}\right)$ \\
\hline
\end{tabular}




\section{Data description}

The analysis of cost structure and efficiency of electricity generation in OECD is hampered by paucity of data for the entire OECD countries. Data collected from different international databases for a period from 1980 to 2009 covers only 25 countries. Years 1980 through to 2009 represent, respectively, the years which data are available for all the variables. The data necessary for the cost estimation include the variable cost, the price of two variable factors i.e labour (L) and fuel (F); a quasi-fixed capital input (K) together with the quantity of electricity generated. Others include carbon emission, electricity reform index regulatory i.e entry barrier, vertical integration, public ownership and overall market reform, as well as the countryspecific heterogeneous variables.

The input prices and variable cost were calculated as follows. The price of labour $\left(w_{1}\right)$ is computed as the ratio of labour compensation ${ }^{10}$ and the number of people engaged obtained from EU KLEMS. This is obtained in each country's currency at current price, and converted to constant price by using value added price index (1995=100). These real local currency measures are then normalised into international units using purchasing power parity exchange rate from Penn World Table (PWT7.1). Fuel price $\left(w_{2}\right)$ represents the price fuel used for electricity generation measured in dollars at current prices. It is obtained from energy, prices and taxes folder of International Energy Agency (IEA). The price is converted to constant price by normalising using price index price index $(1995=100)$ from the World Development Indicators. Data on operating cost was calculated as the sum of labour and fuel expenditures. The number of people represent labour while fuel consumption inputs measured in kilotonnes of oil equivalent (ktoe), and includes all varieties of fuel utilised by the generation plants: coal, oil, gas, hydro, nuclear and biomass. As fuel input data are available in the same measurement units, we aggregated them into one indicator. This allows for the different fuel intensity of different generation technologies. The fuel consumption data is collected from International Energy Agency (IEA).

As for the choice of the outputs, we consider both desirable and undesirable outputs that are jointly produced during electricity and heat production. The outputs are electricity generation $\left(y_{1}\right)$ which represents the annual net electricity output generated by each country measured in gigawatt-hours and carbon emission $\left(y_{2}\right)$ measured in million metric tons. Capital stock is measured in megawatt (MW) of installed capacity. Installed capacity is used as a proxy for the quasi-fixed stock of capital in our cost model. This is a consistent proxy of capital stock in line with relevant papers (See Jaraite \& Di Maria, 2012). Electricity generation and installed capacity are also obtained from International Energy Agency (IEA) while carbon emission is sourced from the World Bank Development Indicator.

\footnotetext{
${ }^{10}$ The data represents labour compensation for utility i.e. water, gas and electricity as there is no available disaggregated for electricity sector. It is reasonable to assume that a substantial portion of the employment in the utility industry is actually attributable to electricity sector.
} 
Besides the standard variables of proper cost estimation, we added electricity sector regulatory reform indicators in the model. The data were obtained from OECD. These include the sub indicators of reform process; namely entry barriers $\left(z_{3}\right)$, public ownership $\left(z_{4}\right)$ and vertical integration $\left(z_{5}\right)$ and overall electricity market reform indicator $\left(z_{6}\right)$. These indicators range from 0 to 6 , with 0 representing the fully open market in which entry barriers, public ownership and vertical integration are minimized and a score of 6 is given to a closed market. Or, as the OECD expresses it: "Scores vary from 0 (the most effective governance structure) to 6 (the least effective governance structure)". Incorporating the variable into the cost frontier, costs are expected to increase with increasing restriction of the electricity market. A positive sign on the market reform variable means that cost rises as index rises from 0 to 6. Moreover, we added countryspecific heterogeneous variables in our analysis to account for possible shifts of frontier cost level. First, we consider electricity consumption per capita $\left(z_{1}\right)$ which tends to strongly correlate with wealth of a country. We expect that countries with high per capita electricity consumption would experience increasing operating costs in order to meet electricity consumption. We also control for degree of industrialisation of each country which is measured by percentage of industrial output share of GDP. We expect a large proportion of industrial customers to increase operating cost in order to a balance industrial electricity demand with energy supply as customer can increase their power demand anytime.

Finally, we included a time trend in the model, measured in years, so as to account for possible effects of Hicks neutral technological change with the expectation that costs are expected to diminish over time, all things being equal. For the estimation, we mean-adjusted all logged for each variable by taking the geometric means in order for the cost order coefficient in the model to be interpreted as elasticities at the sample mean. The descriptive statistics on the variables used in the empirical estimation are provided in Table 2.

Table 2: Descriptive

Statistics

\begin{tabular}{lllrrrr}
\hline & Measurement Units & No of Obs & Mean & Std. Dev. & Min & Max \\
\hline Cost & US \$ (1995=100) & 520 & $1.69 \mathrm{E}+07$ & $4.31 \mathrm{E}+07$ & 7497.12 & $4.31 \mathrm{E}+07$ \\
Electricity generation & GWh & 520 & 370562.20 & 762132.50 & 903.00 & 4190541 \\
Carbon emission & MMT & 520 & 226.59 & 532.18 & 1.03 & 2732.80 \\
Price of labour & US \$ (1995=100) & 520 & 52.36 & 46.51 & 0.65 & 540.48 \\
Price of fuel & US \$ (1995=100) & 520 & 274.70 & 331.53 & 5.40 & 2643.201 \\
Capital & MW & 520 & 90173.52 & 183543.00 & 1235.00 & 1026869 \\
Elect consumption per & kWh per capita & 520 & 6718.95 & 4013.51 & 1226.57 & 17319.23 \\
capita & \% of GDP & 520 & 24.37 & 4.10 & 13.78 & 32.69029 \\
Industrialisation & (0-6) & 520 & 4.10 & 2.46 & 0.00 & 6.00 \\
Entry barriers & & & & &
\end{tabular}


Public ownership

Vertical Integration

Overall elect. Mkt.

reform
(0-6)

(0-6)
520

520

520
4.28

5.45

4.47
2.17

0.80

1.60
0.00

3.00

6.00

6.00

6.00

\section{Results and discussion}

We begin our analysis by running a pooled OLS based on the test proposed by Schmidt and Lin (1984) in order to confirm the presence of technical inefficiency. In the case there were no technical inefficiency, the error term would be distributed symmetrically around zero i.e. $u_{i t}=0$ then $\varepsilon_{i t}=v_{i t}$, thereby invalidating the inefficiency assumption. The estimated skewness (3.66) and kurtosis (15.65) test for normality from the pooled OLS regression has the expected sign and confidently rejects the null hypothesis of normal residual ${ }^{11}$. Thus, the test result provides evidence for the presence of the one-sided error ${ }^{12}$. Furthermore, a series of hypothesis tests were conducted using log likelihood ratio tests. Table 3 presents the results of hypotheses tests that examined a number of restrictions.

Table 3: Likelihood ratio test

\begin{tabular}{llll}
\hline Null Hypothesis & Test statistics & $\begin{array}{l}\text { Critical value } \\
(0.05 \text { level })\end{array}$ & Decision \\
\hline $\begin{array}{l}\text { Cobb-Douglas } \\
H_{0}: \text { all cross effects null }\end{array}$ & 399.21 & $\chi_{14}^{2}=23.68$ & Reject $H_{0}$ \\
$\begin{array}{l}\text { Hicks neutral technical change } \\
H_{0}: \delta_{1}=\delta_{2}=\xi_{1}=\xi_{2}=\eta_{\mathrm{kt}}\end{array}$ & 22.26 & $\chi_{5}^{2}=11.07$ & Reject $H_{0}$ \\
$\begin{array}{l}\text { Homotheticity } \\
H_{0}: \tau_{1}=\tau_{2}\end{array}$ & 112.64 & $\chi_{2}^{2}=5.99$ & Reject $H_{0}$ \\
\hline
\end{tabular}

We test the translog specification against a Cobb-Douglas to confirm if the translog gives adequate representation of the cost structure, and the Cobb-Douglas frontier is rejected, Second, we test the hypothesis of Hick-neutral technological progress that technology change has no effect input augmenting and output demand effects. The hypothesis of technical bias in the translog cost function is also rejected. The homotheticity assumption which states that the level of output has no effect on the input ratios is also tested. We impose restrictions on the 2 parameters associated with interactions between input price and outputs. We reject homotheticity of the technology implying that input prices have significant impact on the scale economies through the cost elasticities of outputs .

Table 4 shows the estimated parameters from the different specifications of the stochastic cost frontier. The first and third columns of results correspond to the fixed and random effects one-way panel model

\footnotetext{
${ }^{11}$ Since our model is cost frontier function with composed error term, the distribution of the OLS residual skew to the right (positive) as against left (negative) for production function regardless of any distributional assumption

${ }^{12}$ The normality result is available.
} 
respectively, while the second column corresponds to the true fixed effects model, TFE. On grounds of the likelihood function values and the significance of the coefficients, the TFE model is clearly preferable. The results in the third column permit derivation of both time-varying and time invariant inefficiency components with latent heterogeneity as well, but only the first step estimates are shown here, which correspond to the random effects version of the fixed effects model in column 1. Again, the precision of the coefficients is less convincing than the true fixed effects model in the second column and moreover the additional time-invariant inefficiency component is minimal. On all these grounds, the TFE model in the second column clearly performs best, and we focus our interpretation on these TFE results.

Table 4 Estimation results:

Translog estimation (Cost)

Determinants of (Cost) in logged mean corrected format

generation

emissions

input price ratio

generation squared

emissions squared

generation-emissions interaction

input price ratio squared

generation-input price interaction

emissions-input price interaction

time

generation-time interaction

emissions-time interaction

input prices-time interaction

capital

capital squared

generation-capital interaction

emissions capital interaction

input prices capital interaction

Increased industrialization

increased entry barriers

increased vertical integration

increased public ownership

reduced overall market reform

constant
Model 3

FWEC-RE

\begin{tabular}{|c|c|c|}
\hline Model 1 FE & Model 2 TFE & $\begin{array}{l}\text { stage } 1 \text { only } \\
\text { Four-way }\end{array}$ \\
\hline $\begin{array}{l}\text { Fixed Effects } \\
\text { for time- } \\
\text { invariant } \\
\text { inefficiency } \\
\text { without } \\
\text { heterogeneity }\end{array}$ & $\begin{array}{l}\text { True fixed } \\
\text { effects for } \\
\text { heterogeneity } \\
\text { with time } \\
\text { varying } \\
\text { inefficiency }\end{array}$ & $\begin{array}{l}\text { component } \\
\text { model with } \\
\text { heterogeneity, } \\
\text { residual and } \\
\text { persistent } \\
\text { inefficiency }\end{array}$ \\
\hline $1.1538 * * *$ & $1.1567 * * *$ & $1.1871 * * *$ \\
\hline 0.0362 & $0.0986 * * *$ & 0.0346 \\
\hline $1.0279 * * *$ & $1.0163 * * *$ & $1.0232 * * *$ \\
\hline $0.2769 * *$ & $0.4572 * * *$ & $-0.2680 *$ \\
\hline 0.0301 & $0.0635^{* * *}$ & 0.0349 \\
\hline-0.1367 & $-0.3719 * * *$ & -0.1141 \\
\hline 0.0004 & -0.0001 & -0.0007 \\
\hline$-0.0682 * *$ & -0.0408 & $-0.0985^{* * *}$ \\
\hline 0.0084 & 0.0012 & 0.012 \\
\hline 0.002 & 0.002 & 0.0005 \\
\hline$-0.0046^{* * *}$ & $-0.0057 * * *$ & -0.0003 \\
\hline-0.0019 & 0.0009 & $-0.0028 *$ \\
\hline-0.0004 & -0.0005 & $-0.0009 *$ \\
\hline$-0.3201 * * *$ & $-0.3219 * * *$ & $-0.2877 * * *$ \\
\hline $0.2390 *$ & $0.2081^{*}$ & $-0.2299 *$ \\
\hline-0.3264 & $-0.4496 * *$ & $0.6034 * *$ \\
\hline 0.0775 & $0.2062 * * *$ & 0.0616 \\
\hline 0.0424 & 0.0299 & $0.0627^{*}$ \\
\hline
\end{tabular}

$\begin{array}{lll}-0.0007 & 0.0004 & -0.0014\end{array}$

$0.0092 \quad 0.0024 \quad 0.0188^{* * *}$

$0.0351^{* * *} \quad 0.0270^{* * *} \quad 0.0421^{* * *}$

$0.0486^{* * *} \quad 0.0334^{* * *} \quad 0.0717^{* * *}$

$-0.0370^{* *} \quad-0.0101 \quad-0.0655^{* * *}$

$-0.5325 * * * \quad$ All $\mathrm{FE}^{* * *} \quad-0.4908 * * *$ 
Est. SE time invariant heterogeneity

Est. SE time invariant inefficiency

Est. SE idiosyncratic error

Est. SE time varying inefficiency

$$
\lambda=\sigma_{u} / \sigma_{v}
$$

Log of likelihood function
0.9352

0.0002

0.0617

$0.0275^{* * *}$

$0.0556^{* * *}$

$2.0223^{* * *}$

739.814

$0.3080 * * *$

$\mathrm{n} / \mathrm{a}$

705.481
$0.0607 * * *$

0.0281

$0.4636 * * *$

Notes: $*, * * * *$ denote statistically significant at $10 \%, 5 \%$ and $1 \%$ respectively.

We discuss several aspects of these results. First, the monotonicity conditions for the translog cost function are clearly satisfied with significant coefficients on the generation, emissions and input price terms. Generation and the input price are the dominant drivers of total costs with a statistically significant but low elasticity of cost arising from emissions handling. The direct impact of neutral technical progress is not significant but there is a significant interaction of technical progress and generation output. This reflects a common finding amongst international panels that it is input accumulation and output expansion that drives productivity over time rather than pure technical progress - see Adetutu et al (2016) for a similar finding for the BRICS economies. The presence of generation capital stock as a quasi-fixed input enables us to estimate the rate of return on capital from the negative of the reported cost elasticity. We see that at a statistically significant sample mean value of 0.3129 the return on capital in generation has been high over the sample period suggesting that producers have been undercapitalised and that expansion of generation investment was warranted compared with the cost of capital that has prevailed in most of the sample countries over this period.

Of primary interest has been the role of regulatory reform and the progress in the product market regulation indicators computed by the OECD. In the first and third columns there is an indication that overall market reform has not reduced cost but this appears to be a spurious finding related simply to the country specific differences across the sample. When country specific latent heterogeneity is allowed for in the TFE results in the second column, which are already preferred for reasons of goodness of fit, it becomes clear that the overall market reform indicator is not statistically significant. In other words the overall reform effort is picked up by the heterogeneity of the countries in the sample; this should not surprise us because each of these countries has pursued different strategies in designing the regulatory oversight and ownership of the generation industry.

On the other hand, two of the OECD's product market regulation indicators are statistically significant even when country-specific heterogeneity is taken into account. These are vertical integration and public 
ownership. Greater vertical integration and a greater degree of public ownership are statistically significant in raising generation costs in each of the estimated models. In the random effects model in the third column barriers to entry are also significant in raising generation costs. We can speculate on the reasons for these findings. Strong vertical integration means that the generation companies are closely allied to the providers of transmission and distribution services. These are invariably in a natural monopoly position of market power so that some protection of market power from competitive forces could be transmitted back up the electrical power supply chain leading to the higher generation costs found in these data. Turning to the impact of public ownership, there is a wide acknowledgement in the literature that public and state owned corporations have a mixed range of objectives that can lead to weaker incentives for cost reduction, and this hypothesis is confirmed by these data.

There are some lessons for the reform process in electricity generation from this research. First, countries have approached the market reform process differently. Inter-country heterogeneity is an important ingredient of the determination of generation costs, and therefore in reviewing lessons from international sample data, significant country differences must be expected. Second, leaving vertically integrated industries intact in the reform process reduces the ability to save generation costs - possibly because of the natural monopoly aspects of the downstream activities. Therefore, unbundling of the industry to create a separate generation sector is likely to enhance efficiency. Third, public and state ownership hinders the reduction in generation costs that can be achieved during periods of market reform. Privatisation appears to be a more efficient policy to pursue. The findings on scale economies in generation alone tell us that taking the quasi-fixed input into consideration, the cost elasticity of scale is 1.05 confirming that a competitive equilibrium in generation without the market power impact of economies of scale is feasible and will permit the unbundling of generation from transmission and distribution.

Scale economies in power generation utilities are the measure of how costs change as the utilities expands all of its productive resources proportionately to provide increased generation. The elasticity of scale is reported in table 5 with $\varepsilon_{1}$ denoting the cost elasticity with respect to electricity generation, $\varepsilon_{2}$ is the cost elasticity with respect to emissions and $\varepsilon_{k}$ represents the cost elasticity with respect to capital. Standard errors and significance tests were constructed using the delta method. We are interested in the difference between the unadjusted measure of scale economies $r$ and the measure adjusted for the quasi-fixed input $r *$

Table 5: Economies of Scale: Inverse of cost elasticity of output vector

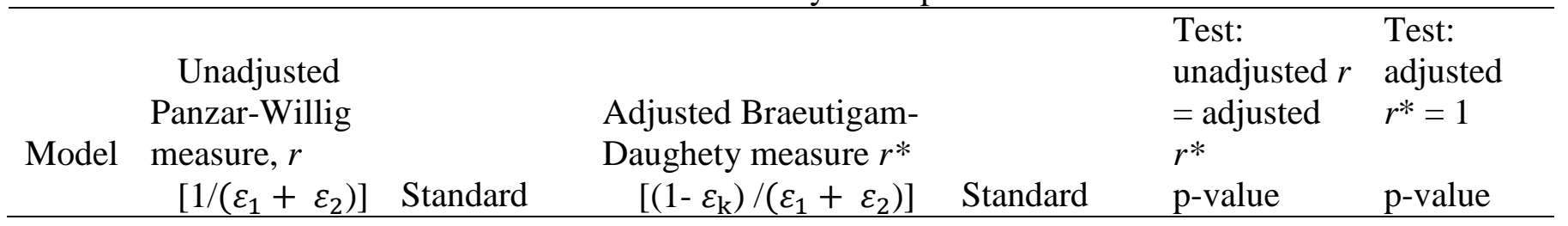




\begin{tabular}{lllllll}
\multicolumn{9}{c}{ error } & error \\
\hline TFE & 0.797 & 0.031 & 1.053 & 0.035 & 0.000 & 0.082
\end{tabular}

The difference in the unadjusted Panzar-Willig versus Brauetigam-Daughety adjusted measures is statistically significant at the 1 percent level so that allowing for the quasi-fixed input is important in discussing economies of scale. As we expected the unadjusted measure reflects the steep curvature of the short run cost function in this capital intensive industry. The adjusted measure is, however, not significantly different from one at the 5 percent level of significance so that we conclude that at the sample mean the generation activity is showing constant returns to scale.

Finally, we present a broad check of the link between market structure variables ${ }^{13}$ and the measured efficiency scores in Table 6.

\section{Table 6}

Pairwise correlations

industrialization

increased entry barriers

increased vertical

integration

increased public ownership

efficiency

$\begin{array}{clll} & \begin{array}{l}\text { increased } \\ \text { entry }\end{array} & \begin{array}{l}\text { increased } \\ \text { vertical } \\ \text { integration }\end{array} & \begin{array}{l}\text { increased } \\ \text { public } \\ \text { ownership efficiency }\end{array} \\ 0.2636^{*} & 1 & & \\ & \text { barriers } & & \end{array}$

Note: * means statistically significant at the 5 per cent level

$\begin{array}{llccl}0.1619 * & 0.3969 * & 1 & & \\ 0.2501^{*} & 0.8495^{*} & 0.2971 * & 1 & \\ 0.0948^{*} & -0.1439^{*} & -0.0895^{*} & -0.1278 * & 1\end{array}$

We see that market reform indicators are themselves positively correlated - so that countries that score poorly on entry barriers or vertical integration for example also score poorly on the other market reform indicators. In terms of the efficiency scores, more industrialized economies have a weak but significant correlation with stochastic efficiency, and countries that have worse (i.e. numerically higher) scores on market reform indicators have lower stochastic efficiency scores with this time the strongest effect from entry barriers.

\section{Conclusion and policy implication}

This study employs different stochastic frontier methods to estimate a short-run equilibrium model of electricity generation variable cost functions in which capital stock is treated as a quasi-fixed input. This is applied to OECD electricity generation sectors while accounting for the impact of electricity market structures by using the published OECD product market reform indicators. Empirical models are developed

\footnotetext{
${ }^{13}$ We exclude the overall market reform indicator from this table because the efficiency scores are from the TFE model where its effect is submerged in the country-specific latent heterogeneity fixed effects
} 
for the variable cost function as a translog form and analysed using panel data of 25 countries during the period 1980 to 2009. We use three main estimation models: Schmidt-Sickles (1984) fixed effects, Greene (2005) True fixed effects which includes country specific latent heterogeneity and Kumbhakar, Lien and Hardakar (2014) four-way error component effects which accounts for time-invariant inefficiency by disentangling time-invariant (persistent) inefficiency from time-invariant heterogeneity. Our results show that cost efficiency scores as well as their ranking depends are sensitive to the choice of model specification. We find efficiency score from the Schmidt-Sickles fixed effects model to be much more lower than in other models as a result of treating unobserved country effects as inefficiency. The true fixed effects model is most successful since the additional time-invariant inefficiency component of the four-way model is negligible. The results reveal the underlying importance of accounting for unobserved heterogeneity, and distinguishing it from inefficiency.

Our results show the significant influence of electricity market regulatory reform index on cost of electricity generation. On one hand, public ownership and vertical integration are found to be associated with high efficiency loss while no statistically significant relationship established for entry barriers. This result reiterates the benefit of privatisation of generation assets and private ownership in power sector. Our results have important policy implications for the electricity market reform agenda. The nature of the deregulation matters since unbundling and privatization are the factors which encourage the generation utility to make maximum use of least cost options for efficiency gain. On the other hand, overall electricity market reform shows evidence of cost reduction only when unobserved heterogeneity is not treated separately from inefficiency.

The estimated economies of output expansion for the models in the short run is about 0.8 , indicating the existence of sharply rising costs when capacity is fixed. However, economies scale in the long run are measured at 1.05 - and not significantly different from 1, implying constant returns to scale when adjustment is made for the quasi-fixed input.. Thus, policymakers can create conditions that encourage more competition among generators in order to encourage investment in the industry since we find a high return to capital investment when we model the shadow price of the quasi-fixed capital input. Finally we find that market reforms are positively correlated - a country pursuing one type of reform often pursues others as well - and that these market structure reforms as measured by the OECD product market reform indicators produce more cost-efficient electricity generation. 


\section{References}

Adetutu et al 2016 Adetutu Morakinyo, Anthony Glass and Thomas Weyman-Jones (2016) “Decomposing Energy Demand across the BRIIC Countries” Energy Economics 54, 395-404

Akkemik, K. A., 2009. Cost function estimates, scale economies and technological progress in the Turkish electricity generation sector. Energy Policy, 37(1), 204-213.

Al-Sunaidy, A., \& Green, R., 2006. Electricity deregulation in OECD (Organization for Economic Cooperation and Development) countries. Energy, 31(6), 769-787

Arcos, A., \& De Toledo, P. A., 2009. An analysis of the Spanish electrical utility industry: Economies of scale, technological progress and efficiency. Energy Economics, 31(3), 473-481.

Assaf, A. G., Barros, C. P., \& Managi, S., 2011. Cost efficiency of Japanese steam power generation companies: a Bayesian comparison of random and fixed frontier models. Applied Energy, 88(4), 1441-1446.

Braeutigam, R. R., \& Daughety, A. F., 1983. On the estimation of returns to scale using variable cost functions. Economics Letters, 11(1), 25-31.

Braeutigam, R. R., Daughety, A. F., \& Turnquist, M. A., 1984. A firm specific analysis of economies of density in the US railroad industry. The Journal of Industrial Economics, 3-20.

Baumöl, W. J., 1975. Scale Economies, Average Cost and the Profitability of Marginal Cost Pricing.

Burns, P., \& Weyman-Jones, T. G., 1996. Cost functions and cost efficiency in electricity distribution: A stochastic frontier approach. Bulletin of Economic Research, 48(1), 41-64.

Cowing, T. G., Small, J., \& Stevenson, R. E., 1981. Comparative measures of total factor productivity in the regulated sector: The electric utility industry. Productivity measurement in regulated industries, 161-177.

Considine, T. J., 2000. Cost structures for fossil fuel-fired electric power generation. The Energy Journal, 83-104.

Christensen, L. R., \& Greene, W. H., 1976. Economies of scale in US electric power generation. The Journal of Political Economy, 655-676.

Douglas, S., Garrett, T. A., \& Rhine, R. M., 2009. Disallowances and overcapitalization in the US electric utility industry. Federal Reserve Bank of St. Louis Review, 91(1), 23-31.

Fan, Y., Li, Q., \& Weersink, A., 1996. Semiparametric estimation of stochastic production frontier models. Journal of Business \& Economic Statistics, 14(4), 460-468.

Faust, A. K., \& Baranzini, A., 2014. The economic performance of Swiss drinking water utilities. Journal of productivity analysis, 41(3), 383-397.

Filippini, M., \& Wetzel, H., 2014. The impact of ownership unbundling on cost efficiency: Empirical evidence from the New Zealand electricity distribution sector. Energy Economics, 45, 412-418.

Filippini, M., 1996. Economies of scale and utilization in the Swiss electric power distribution industry. Applied Economics, 28(5), 543-550. 
Filippini, M., 1996. Economies of scale and utilization in the Swiss electric power distribution industry. Applied Economics, 28(5), 543-550.

Filippini, M., \& Wild, J., 2001. Regional differences in electricity distribution costs and their consequences for yardstick regulation of access prices. Energy Economics, 23(4), 477-488

Friedlaender, A. F., \& Spady, R. H., 1981. Freight transport regulation: Equity, efficiency, and competition in the rail and trucking industries. MIT Press.

Giles, D. E., 1989. Economies of scale in the New Zealand electricity distribution industry (No. 8904). Department of Economics, University of Canterbury.

Gilsdorf, K., 1994. Vertical integration efficiencies and electric utilities: a cost complementarity perspective. The Quarterly Review of Economics and Finance, 34(3), 261-282.

Hattori, T., Jamasb, T., \& Pollitt, M. G., 2003. A comparison of UK and Japanese electricity distribution performance 1985-1998: lessons for incentive regulation.

Hiebert, L. D., 2002. The determinants of the cost efficiency of electric generating plants: a stochastic frontier approach. Southern Economic Journal, 935-946.

Hovde, D. A., Irwin, L., Islam, M., \& Rose, K., 1996. Economies of scale and vertical integration in the investor-owned electric utility industry. National Regulatory Research Institute, Ohio State University

Joskow, P.L., 2008. Lessons Learned from the Electricity Market Liberalization, The Energy Journal, Vol. 29 (special issue), pp. 9-42.

Kamerschen, D. R., \& Thompson, H. G., 1993. Nuclear and fossil fuel steam generation of electricity: differences and similarities. Southern Economic Journal, 14-27.

Kaserman, D. L., \& Mayo, J. W., 1991. The measurement of vertical economies and the efficient structure of the electric utility industry. The Journal of Industrial Economics, 483-502.

Kleit, A. N., \& Terrell, D., 2001. Measuring potential efficiency gains from deregulation of electricity generation: A Bayesian approach. Review of Economics and Statistics, 83(3), 523-530

Kopsakangas-Savolainen, M., \& Svento, R., 2008. Estimation of cost-effectiveness of the Finnish electricity distribution utilities. Energy Economics, 30(2), 212-229.

Koske, I., Wanner, I., Bitetti, R., \& Barbiero, O., 2015. The 2013 update of the OECD's database on product market regulation.

Kumbhakar, S. C., Lien, G., \& Hardaker, J. B., 2014. Technical efficiency in competing panel data models: a study of Norwegian grain farming. Journal of Productivity Analysis, 41(2), 321-337.

Krautmann, A. C., \& Solow, J. L., 1988. Economies of scale in nuclear power generation. Southern Economic Journal, 70-85.

Kwoka Jr, J. E., 2005. Electric power distribution: economies of scale, mergers, and restructuring. Applied Economics, 37(20), 2373-2386. 
Maloney, M. T., 2001. Economies and diseconomies: estimating electricity cost functions. Review of industrial organization, 19(2), 165-180.

Nelson, R. A., 1989. On the measurement of capacity utilization. The Journal of Industrial Economics, 273286.

Nelson, R. A., 1985. Returns to scale from variable and total cost functions: Evidence from the electric power industry. Economics Letters, 18(2), 271-276.

Nelson, R. A., \& Wohar, M. E., 1983. Regulation, scale economies, and productivity in steam-electric generation. International Economic Review, 57-79.

Nemoto, J., Nakanishi, Y., \& Madono, S., 1993. Scale economies and over-capitalization in Japanese electric utilities. International Economic Review, 431-440.

Nerlove, M., 1961. Returns to scale in electricity supply. Institute for mathematical studies in the social sciences.

Nillesen, P.H.L., Pollitt, M.G., 2011. Ownership unbundling in electricity distribution: empirical evidence from New Zealand. Review industrial organization, . 38, 61-93.

Oum, T. H., \& Zhang, Y., 1991. Utilisation of quasi-fixed inputs and estimation of cost functions: an application to airline costs. Journal of Transport Economics and Policy, 121-134.

Pielow, J.C., Brunekreeft, G., Ehlers, E., 2009. Legal and economic aspects of ownership unbundling in the EU. J. World Energy Law Bus. 2, 96-116.

Panzar, J. C., \& Willig, R. D., 1977. Economies of scale in multi-output production. The Quarterly Journal of Economics, 481-493.

Pollitt, M.G., 2008. The arguments for and against ownership unbundling of energy transmission networks. Energy Policy 36, 704-713.

Pollitt, M., 2008. The arguments for and against ownership unbundling of energy transmission networks. Energy policy, 36(2), 704-713.

Ramos-Real, F. J., 2005. Cost functions and the electric utility industry. A contribution to the debate on deregulation. Energy Policy, 33(1), 69-87.

Rhine, R., 2001. Economies of scale and optimal capital in nuclear and fossil fuel electricity production. Atlantic Economic Journal, 29(2), 203-214.

Rungsuriyawiboon, S., \& Stefanou, S. E., 2007. Dynamic efficiency estimation: an application to US electric utilities. Journal of Business \& Economic Statistics, 25(2), 226-238.

Vita, M. G., 1990. Exploring hospital production relationships with flexible functional forms. Journal of Health Economics, 9(1), 1-21.

Wang, Y. S., Xie, B. C., Shang, L. F., \& Li, W. H., 2013. Measures to improve the performance of China's thermal power industry in view of cost efficiency. Applied Energy, 112, 1078-1086. 
Yatchew, A., 2000. Scale economies in electricity distribution: A semiparametric analysis. Journal of Applied Econometrics, 15(2), 187-210. 